special work. I see in some exemplified to an bathing the parts therein until the amount used extreme degree the studious, careful and success- for injection is exhausted from the bag.

ful diagnostician; in some, the same tendencies toward careless diagnoses; in others, the evils of false diagnoses in special lesions, with the of ten fatal reluctance to resort to mechanical treatment when that treatment is indispensable.

The remedies suggested for surgeons apply to physicians, except that to the latter the importance of indications for operation rather than contra-indications should be emphasized, for, however undesirable, in the abstract, surgery may be, its results as a whole are wonderfully good.

\section{OTiniral פDepartment.}

\section{HYGIENIC ADJUSTABLE BATH DOUCHE HAMMOCK.}

A New Method of Properly Administering a Vaginal Douche and a Rectal Enema.

BY G. L. IIAGENBURGER, M.D., BOSTON.

$A$. Few women know and few physicians sufficiently instruct their patients as to the proper position necessary to obtain the real benefit that is derived from hot water (plain or medicated) either for hygienic purposes, such as cleansing and washing out, or for the depleting effect upon the uterus, tubes, ovaries or the pelvic organs in general when congested or inflamed. It is surprising upon investigation to see what a small number of physicians, so small I dare not fix the percentage, when they order a plain or medicated douche to their patients, understand the significance of their advice.

The patient returns home, fills the douche bag, lies down flat on the bed, couch or sits down in squatter fashion, which is worse, inserts the nozzle of the syringe, the fluid reaches the vulva or lower portion of the vagina, if nozzle is straight; if the same is slightly turned to one side the fluid is sent against the vaginal wall and escapes. The therapeutic effect upon the parts as intended is nil, because they are not and cannot be reached in this way. Congestion and inflammation goes on until surgical remedial measures are resorted to, which in many cases might be prevented. Why? Because the modus operandi is wrong, because the attendant has not taken into consideration the proper anatomical relations of the female genital organs when diseased.

The patient gets little or no benefit, becomes discouraged, gets the fluid on her clothing, bed, couch, floor; in fact, everywhere except in the vagina proper, where it will have some remedial effect upon the inflamed organs. Physicians condemn douches, not because hot water is ineffective on inflamed organs, but on account of the error in placing the patient in a proper position so that the water injected will not only come in direct contact with all the parts to be reached, but to remain there for some length of time, thus making a well out of the vagina, keeping a residual amount of fluid continuously surrounding and
For the past ten years I have instructed my patients to have a cover made, three quarters of the length of the bath tub, with a rubber or oilcloth pillow (stuffed with shavings or excelsior), this to be placed under the buttocks, which aro raised, and the upper portion of the body lowered (Trendelenburg's position). 'The time spent in explaining this method to patients and physicians was well spent indeed considering the benefit my patients derived from that position in so douching and thus saving many a patient from the operating table. Now I have devised a hammock which attaches to any bath tub as per cut, upon which the patient lies with her hips lowering the upper portion of the body on an incline of $25^{\circ}$, thus drawing the abdominal contents towards the diaphragm, making a receptacle or reservoir of the vagina capable of holding an amount of water in reserve, continuously surrounding and bathing the cervix, and the vaginal walls, which, in my

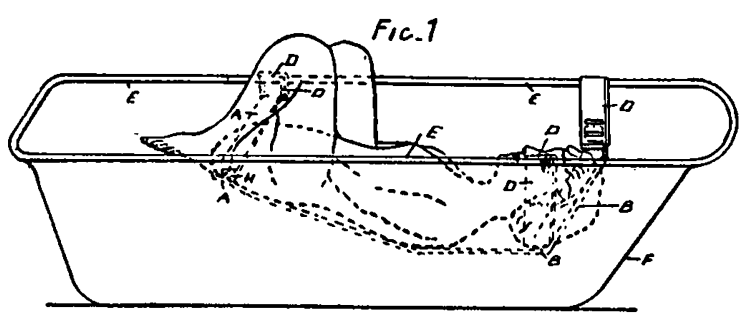

opinion, is the only proper method of doing what the douche is intended to do, viz., relieve engorgement and inflammation when existent in the pelvic organs.

I have carried on experiment after experiment by placing small pieces of litmus paper, gauze, cotton or small pieces of permanganate of potassium in under the cervix and asked the patient to take a douche as she is in the habit of taking it, lying flat on a Kelly pad, only to find after the completion of the douche none of the abovementioned articles in the returned fluid, but find them upon examination with the speculum where previously placed. By putting my patients in the proper position as above described and watching the return flow these substances are found therein instead of remaining upon the vaginal walls. The same holds good of vaginal secretions, benign or specific in character. In order to make any beneficial impressions upon inflamed organs it is necessary that the hot water must remain in a direct or indirect contact with these parts, not simply sent in and out. This cannot be done except the vagina is made to act as a reservoir which retains for the time being a residual amount of fluid. A sprinkling process merely will not answer. This device is simple, inexpensive and can be hung in any bath tub; no clothes, bedding, pillows or floors to get wet; the water drains off into the bath tub and, therefore, patients will use a larger amount of water and in the proper way where a douche is indicated.

$B$. The same hammock can be used for giving 
a high enema. It is a known fact that in order to wash out the entire lower bowel a high rectal tube must be inserted in the rectum by one experienced in doing it, a physician or nurse. If this is not done and the patient takes an enema by inserting the nozzle of the syringe into the rectum lying flat, after it bellows up the rectum, the water returns, bringing the feces below the sigmoid flexure with it, and that is all.

By placing the patient in this hammock, buttocks raised, body lowered, the rectum is sufficiently filled with water pressing upon the valve of the sigmoid, and by gravity passes over and into the ascending, transverse, and descending colon

$$
\text { Fic.2 }
$$

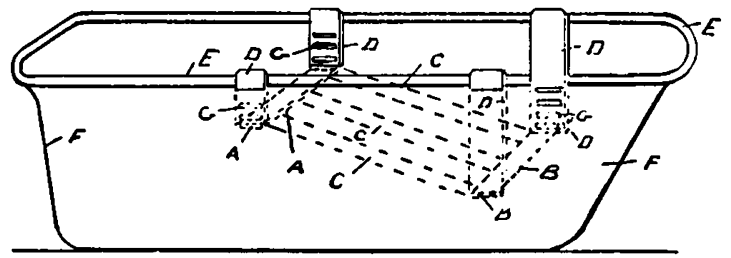

and cecum, thus washing out the entire large intestine as is accomplished only by a high enema. It is desirable after half the amount of the injected fluid is used up for the patient to turn slightly to the right, which facilitates the fluid flowing over the transverse colon into the cecum.

Do away with the tube, especially in sigmoiditis or ulcerative conditions of the large bowel, where the passing of the tube is contra-indicated or painful, and where plain or medicated lavage is desired or indicated.

In case the patient is unable to leave the bed the hip strap of the hammock can be hung upon two stands, one on each side of the bed, the hips raised upon it and the douche or enema given without removing the patient to the bath tub.

\section{Mredical Brogregg.}

\section{PROGRESS IN SURGERY.}

BY JAMES G. MUMFORD, M.D., BOSTON.

(Concluded from No. 23, p. 763.)

\section{ARTIFICIAL RESPIRATION AND OPERATIONS} WITHIN THE THORAX.

IN addition to these conclusions, Robinson made sundry other interesting reflections upon the problems we are discussing, - that one side of the human chest is often and safely opened without the use of any apparatus, while certain chest operations which prove fatal to the normal dog are almost invariably harmless in the case of human beings. This seeming paradox has frequently been explained, and the explanation rests on two facts - the mediastinal partition in dogs is little more than a fluttering membrane, which gives way readily to pressure, and operations upon the chest in human beings are usually conducted in the presence of extensive adhesions which fortify the normal partition.
Willy Meyer, speaking at this symposium, while recognizing the value of much of the positive pressure work which has been done, pointed out a fact which must appeal to every practical clinician - the fact that any positive pressure apparatus must interfere with the anesthetist's control of the patient's throat and jaws in the case of vomiting and collapse. Robinson meets this objection by placing promptly over the thoracic wound a perfectly fitting glass cup, and then removing the apparatus from the patient's face. Critics may retort that this maneuver may be troublesome and awkward in case of a serious anesthetic emergency.

Nathan W. Green and J. W. Draper Maury, of New York, followed Robinson with an interesting paper on the application of the positive pressure method to the surgery of the thoracic portion of the esophagus. Students of the literature will recall Green's article on the positive pressure method, published two years ago, ${ }^{4}$ and the preliminary report by Green and Maury published last year. ${ }^{5}$ In their present article they have little to add to their statements regarding methods of artificial respiration, but deal largely with the technic of esophageal resections, - a matter which is not especially pertinent to our discussion. Suffice it to say that Green continues to use, and apparently with satisfaction, a method of positive pressure. His present paper is based upon work performed in the surgical research laboratory of the College of Physicians and Surgeons. Both in this paper and in his previous writing, Green asserts his confidence in the apparatus of Brauer, or in the ingenious modification of it by $\mathrm{F}$. T. Murphy.

Other experimenters affirm their satisfaction with a positive pressure method. H. H. Janeway, among them, tells of his using the box designed by F. T. Murphy.

In view of these encouraging and cogent statements of many investigators regarding positive pressure, it is interesting to turn to the reports and the work of E. F. Sauerbruch, of Marburg. It is now nearly five years since Sauerbruch, ${ }^{6}$ at the German Surgical Congress, brought clearly to our notice the advantages of his negative pressure apparatus for artificial respiration. He agreed with most other observers in dwelling upon the dangers of pneumothorax, and described that form of apparatus which is now familiarly known as the "Sauerbruch Pneumatic Cabinet." Last June, in Chicago, Sauerbruch rehearsed the points in his well-known work and dwelt especially upon certain features of his investigation, stating that dissatisfaction with the theory of positive pressure, and the encouragement of Von Mikulicz, led him to experiment with negative pressure, basing his work on the known principles of the difference between the intrabronchial pressure and the pressure at the surface of the pleura about 7 to $8 \mathrm{~mm}$. of mercury - which serves to

1 "The Positive Pressure Method of Artificial Respiration." Surg., Gynec. and Obstet.. May, 1906.

${ }_{5}$ "Experimental Studies upon the Thoracic Esophagus; A Pre-

6 iminary Report." Ann. Surg., October, 1907. 